\title{
SISTEM PENGGAJIAN KARYAWAN PADA LKP GRACE EDUCATION CENTER
}

\author{
Muhammad Dedi Irawan*1, Laila Hasni² \\ ${ }^{* 1,2}$ Universitas Asahan; J1. Ahmad Yani Kisaran Telp. (0623) 456222 \\ *1,2Program Studi Teknik Informatika, Fakultas Teknik Una, Kisaran Sumatera Utara \\ temansejati.dedi@gmail.com ${ }^{1}$,laylahasni13@gmail.com ${ }^{2}$
}

\begin{abstract}
ABSTRAK - Banyak instansi maupun perusahaan dituntut untuk memodernisasi manajemen pengelolaanya dari sistem manual ke sistem terkomputerisasi. LKP Grace Education Center adalah sebuah lembaga yang berdiri dibidang pendidikan tempat kegiatan utamanya adalah melayani dan memberikan pelayanan terbaik, dan juga memperkerjakan cukup banyak karyawan, sistem penggajian yang sedang berjalan pada LKP Grace Education Center masih menggunakan cara tradisional/manual. Keterlambatan sering terjadi dalam memproses gaji karyawan akibat penumpukan pemrosesan pembayaran gaji yang masih dilakukan secara tradisional/manual, karena data harus dicatat atau diproses berulangkali dalam upaya menyusun laporan gaji karyawan. Dengan adanya sistem yang terkomputerisasi diharapkan dapat meningkatkan efisiensi kerja, kecepatan, dan ketepatan dalam suatu pengambilan keputusan. Dalam upaya mencegah kecurangan-kecurangan yang mungkin terjadi terhadap penggajian kepada para tenaga kerja maka diperlukan adanya sistem informasi penggajian, dimana terdapat formulir-formulir, catatancatatan dan prosedur-prosedur yang digunakan untuk menetapkan gaji yang harus diberikan kepada para tenaga kerja.
\end{abstract}

Kata Kunci : Sistem, Penggajian, Karyawan.

ABSTRACT - Many agencies and companies are required to modernize their management from manual system to computerized system. LKP Grace Education Center is an educational institution where the main activity is to serve and provide the best service, and also employ enough employees, the payroll system that is running on LKP Grace Education Center still using traditional / manual way. Delay often occurs in processing employee salaries due to the accumulation of processing payroll salaries that are still done traditionally / manual, because the data should be recorded or processed repeatedly in an effort to compile employee salary reports. With the existence of a computerized system is expected to improve work efficiency, speed, and accuracy in a decisionmaking. In order to prevent possible frauds from paying to the workers there is a need for a payroll information system, where there are forms, notes and procedures used to establish salaries to be paid to workers.

Keywords: System, Payroll, Employee.

\section{PENDAHULUAN}

Perkembangan Teknologi Informasi (TI) saat ini berkembang sangat pesat baik perangkat keras maupun perangkat lunak, sehingga hampir semua pekerjaan manusia dapat diselesaikan dengan komputer. Dengan demikian, dapat dikatakan bahwa komputer merupakan alat bantu manusia dalam menyelesaikan pekerjaannya. Hal ini mengakibatkan instansi swasta maupun negeri, berlomba- lomba untuk meningkatkan kinerjanya dengan mengambil langkah-langkah terbaik, agar dapat mengatasi persaingan diberbagai bidang.
Pentingnya sistem informasi dalam penggajian bagi perusahaan adalah untuk menghindari terjadinya kesalahan, penyimpangan atau pengeluaran perusahaan yang fiktif sehingga dapat menimbulkan kerugian pada perusahaan,

Dengan adanya sistem yang terkomputerisasi diharapkan dapat meningkatkan efisiensi kerja, kecepatan, dan ketepatan dalam suatu pengambilan keputusan. Dalam upaya mencegah kecurangan-kecurangan yang mungkin terjadi terhadap penggajian kepada para tenaga kerja maka diperlukan adanya sistem informasi penggajian, dimana terdapat formulir-formulir, 
catatan-catatan dan prosedur-prosedur yang digunakan untuk menetapkan gaji yang harus diberikan kepada para tenaga kerja. Untuk menjamin kelangsungan dan kesungguhan para tenaga kerja dalam melaksanakan tugasnya, pihak manajemen dituntut agar menentukan gaji yang sesuai dengan keahlian, jabatan, pendidikan, masa kerja, pengalaman, kondisi perusahaan, upah minimum regional (UMR) serta peraturan penggajian yang ditetapkan oleh pemerintah sesuai dengan UUD.

Banyak instansi maupun perusahaan dituntut untuk memodernisasi manajemen pengelolaanya dari sistem manual ke sistem terkomputerisasi. LKP Grace Education Center adalah sebuah lembaga yang berdiri dibidang pendidikan tempat kegiatan utamanya adalah melayani dan memberikan pelayanan terbaik, dan juga memperkerjakan cukup banyak karyawan, sistem penggajian yang sedang berjalan pada LKP Grace Education Center masih menggunakan cara tradisional/manual. Keterlambatan sering terjadi dalam memproses gaji karyawan akibat penumpukan pemrosesan pembayaran gaji yang masih dilakukan secara tradisional/manual, karena data harus dicatat atau diproses berulangkali dalam upaya menyusun laporan gaji karyawan.

\subsection{Pengertian sistem}

Menurut Mulyadi (dalam Devi Lestari : 2014 : 23) Sistem pada dasarnya adalah sekelompok unsur yang erat berhubungan satu dengan lainnya, yang berfungsi bersama-sama untuk mencapai tujuan tertentu.

Menurut James A. Hall (2001 : 5)

Sebuah sistem adalah sekelompok dua atau lebih komponen-komponen yang saling berkaitan (inter-related) atau subsistem subsistem yang bersatu untuk mencapai tujuan yang sama (common purpose)."

\subsection{Karakteristik Sistem}

Menurut Jogiyanto (dalam Muhammad Ilham : 2013 : 12 ) Suatu sistem mempunyai karakteristik atau sifat-sifat tertentu yaitu :

1. Komponen-komponen (components)

Komponen-komponen satu sistem dapat berupa suatu subsistem atau bagian-bagian dari sistem yang mempunyai sifat dari sistem yang menjalankan fungsi tertentu dan mempengaruhi proses sistem secara keseluruhan.

2. Batasan Sistem (boundry)

Batas sistem merupakan daerah yang membatasi antara suatu sistem dengan sistem lainnya atau dengan lingkungan luarnya.

3. Lingkungan Luar Sistem (environment) Lingkungan luar sistem adalah apapun diluar batas sistem yang mempengaruhi operasi sistem.

4. Penghubung Sistem (interface)

Penghubung sistem merupakan media penghubung antara suatu subsistem dengan subsistem yang lain untuk berinteraksi membentuk satu kesatuan.

5. Masukan Sistem (input)

Masukan adalah energi yang dimasukan kedalam sistem. Masukan dapat berupa masukan perawatan (maintenance input) dan masukan sinyal (signal input).

6. Keluaran Sistem (output)

Keluaran adalah hasil dari energi yang diolah dan diklasifikasikan menjadi keluaran yang berguna dan sisa pembuangan.

7. Pengolah Sistem

Suatu sistem dapat mempunyai suatu bagian pengolah yang akan merubah masukan menjadi keluaran.

8. Sasaran sistem.

Suatu sistem pasti mempunyai tujuan ( goal) atau sasaran (objectives). Sasaran dari sistem sangat menentukan sekali masukan yang dibutuhkan sistem dan keluaran yang akan dihasilkan sistem.

\subsection{Pengertian Informasi}

Menurut Jogiyanto Hartono (2005) "informasi adalah data yang di olah menjadi bentuk yang lebih berguna dan lebih berarti bagi penerimanya". Kualitas dari suatu informasi (quality of information) tergantung dari tiga hal, yaitu informasi harus akurat (accurate), tepat waktu (timeliness), dan relevan (relevance).

\subsection{Pengertian Sistem Informasi}

Menurut Jogianto (dalam Zulnalis : 2016

: 206), "Sistem Informasi didefinisikan oleh

Robert A. Leitch dan K. Roscoe Davis: adalah 
suatu sistem dalam suatu organisasi yang mempertemukan kebutuhan pengolahan transaksi harian, mendukung operasi, bersifat manajerial dan kegiatan strategi dari suatu organisasi dan menyediakan pihak luar tertentu dengan laporanlaporan yang digunakan".

\subsection{Karyawan}

Menurut Hasibuan (dalam Suginam dkk. : 2017 : 344) karyawan adalah setiap orang yang bekerja dengan menjual tenaganya (fisik dan pikiran) kepada suatu perusahaan dan memperoleh balas jasa yang sesuai dengan perjanjian. Sedangkan menurut kamus besar bahasa indonesia karyawan merupakan orang yang bekerja pada suatu lembaga (kantor, perusahaan) dengan mendapatkan gaji (upah).

\subsection{Gaji}

Menurut Sadono Sukirno (2004) gaji merupakan pembayaran langsung didasarkan pada periode waktu tertentu dari waktu kerja, seperti seminggu, sebulan atau setahun.

Menurut Mulyadi (dalam Deni Tri Setiawan : 2014 : 33) penggajian adalah "pembayaran atas penyerahan jasa yang dilakukan oleh karyawan administrasi atau yang mempunyai jenjang jabatan yang pada umumnya dibayarkan secara tetap per bulan."

1.7 Metode Analisa dan Perancangan Terstruktur

\subsubsection{Diagram Konteks}

Diagram konteks merupakan langkah awal dari analisis struktur dan level teratas dari diagram arus data dan merupakan penggambaran sistem secara garis besar. Diagram konteks menggambarkan hubungan aliran-aliran data kedalam dan keluar sistem atau entitas-entitas yang terletak diluar sistem (output) atau menerima data dari sistem tersebut (input). Satu hal yang perlu diperhatikan, diagram konteks hanya menggunakan satu lingkungan proses yang mewakili proses dari semua sistem (Rifky Sahib Nugraha 2009:54).

Tabel 3.1 Simbol-Simbol Diagram Konteks

\begin{tabular}{|c|c|c|c|}
\hline No & Simbol & Pengertian & Keterangan \\
\hline 1 & & Eksternal Entity & $\begin{array}{l}\text { Menunjukan bagian luar } \\
\text { sistem atau sumber input } \\
\text { dan output }\end{array}$ \\
\hline 2 & $\longrightarrow$ & Garis aliran & $\begin{array}{l}\text { Menunjukan arus sata } \\
\text { antar simbol/proses }\end{array}$ \\
\hline 3 & & Sistem & Menunjukan sistem \\
\hline
\end{tabular}

\subsubsection{Data Flow Diagram}

Data Flow Diagram (DFD) juga di kenal sebagai model proses (process model) merupakan sebuah teknik analisis yang digunakan untuk menggambarkan aliran input dalam sebuah sistem (sekumpulan proses) serta output yang dihasilkan. DFD menggambarkan apa yang terjadi dalam sebuah sistem. Lebih mudah untuk melihat gambar dan memahami isinya dibandingkan dengan membaca banyak dokumen yang menerangkan sebuah sistem.

Data Flow Diagram (DFD) adalah alat pembuatan model yang memungkinkan profesional sistem untuk menggambarkan sistem 
sebagai suatu jaringan proses fungsional yang dihubungkan satu sama lain dengan alur data, baik secara manual maupun komputerisasi. DFD ini sering disebut juga dengan nama Bubble chart,
Bubble diagram, model proses, diagram alur kerja, atau model fungsi. (Rifky Sahib Nugraha 2009:54).

Tabel 3.2 Simbol-Simbol Data Flow Diagram (DFD)

\begin{tabular}{|c|c|c|c|}
\hline No & Simbol & Nama & Keteranngan \\
\hline 1 & & Entitas & $\begin{array}{l}\text { Kesatuan luar yaitu kesatuan diluar lingkungan luar } \\
\text { sistem yang berada dilingkungan luarnya, yang } \\
\text { akan memberikan input atau menerima output dari } \\
\text { sistem Orang atau organisasi diluar system tetapi } \\
\text { berinteraksi dengan sistem. }\end{array}$ \\
\hline 2 & Atau & Proses & $\begin{array}{l}\text { Aktivitas atau fungsi yang membentuk tugas } \\
\text { khusus, dapat manual atau terkomputerisasi. }\end{array}$ \\
\hline 3 & & Data store & Sekumpulan data yang tersimpan secara permanen \\
\hline 4 & & Data flow & Penghubung dalam sebuah sistem \\
\hline
\end{tabular}

\section{METODE PENELITIAN}

Metode penelitian adalah cara-cara untuk mendapatkan segala informasi yang dibutuhkan dalam penyusunan, dan untuk itu digunakan beberapa metode penelitian :

1. Penelitian Lapangan (Field Research)

Penelitian ini penulis lakukan langsung di lapangan dengan menganalisa masalah terhadap objek gang telah dipilih. Dalam hal ini penulis mendahulukan penelitian (peninjauan) langsung ke LKP Grace Education Center Kecamatan Lima Puluh Kabupaten Batu Bara
2. Wawancara

Selanjutnya melaksanakan wawancara dengan pihak yang bersangkutan dan observasi sehingga diperoleh data yang diperlukan dalam penulisan laporan kerja praktek.

3. Penelitian Kepustakaan (Library Research) Penulis mengumpulkan jurnal, artikel dan data dari buku-buku yang berkaitan dengan masalah yang akan dibahas. 


\section{HASIL DAN PEMBAHASAN}

\subsection{Analisa Sistem}

Analisis sistem adalah penguraian dari suatu sistem informasi yang utuh ke dalam komponen-komponennya dengan maksud untuk mengidentifikasikan dan mengevaluasi permasalahan-permasalahan, kesempatan- kesempatan, hambatan-hambatan yang terjadi dan kebutuhan-kebutuhan yang diharapkan.

\subsubsection{Diagram Konteks (Conteks Diagram)}

Diagram konteks merupakan alat untuk struktur analisis yang menggambarkan sistem secara umum. Sistem Informasi yang dibuat akan menghasilkan sumber informasi yang dibutuhkan dan tujuan informasi yang dihasilkan.

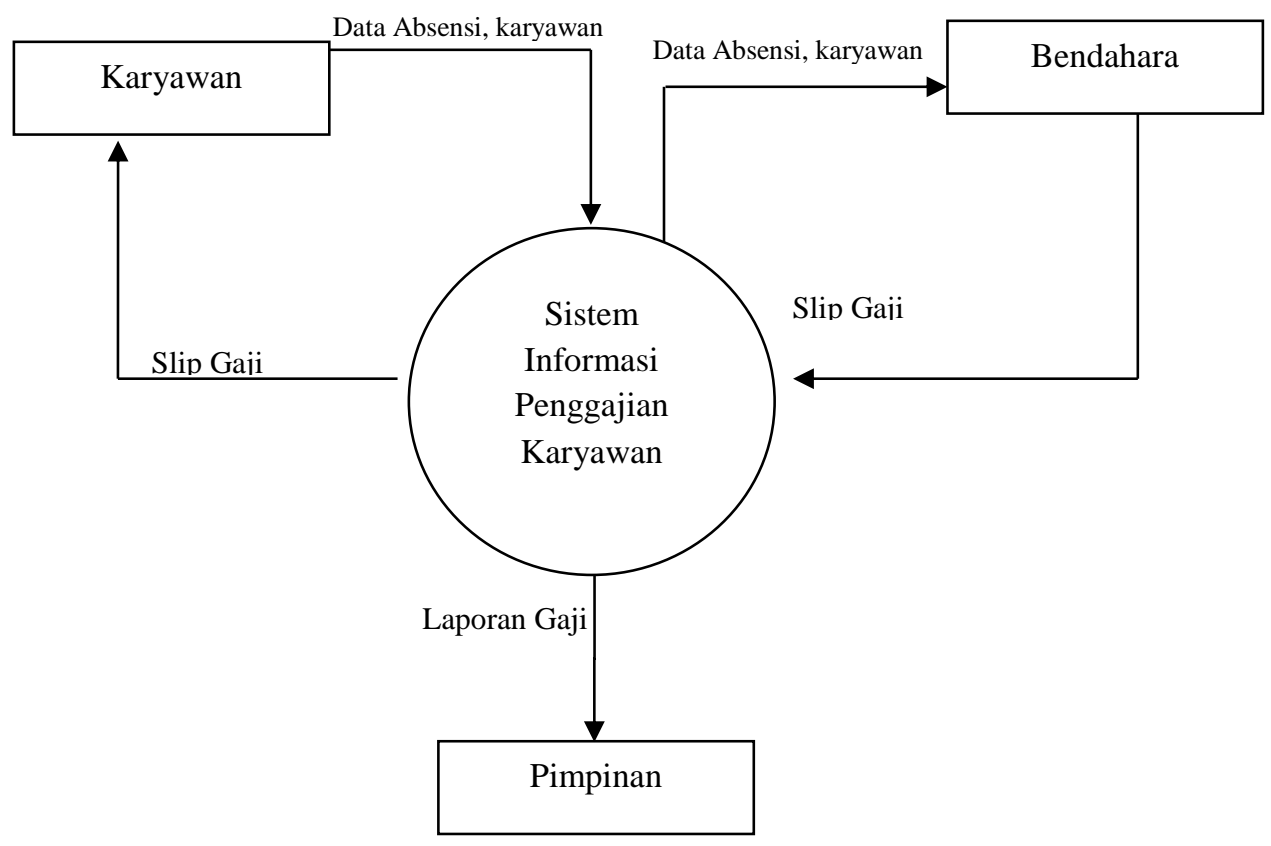

Gambar 3.1 Diagram Konteks Penggajian Karyawan 


\subsubsection{Data Flow Diagram (DFD)}

DFD (Data Flow Diagram) merupakan alat pada metodologi pengembangan sistem secara terstruktur, yang menggambarkan alur data dari suatu sistem.

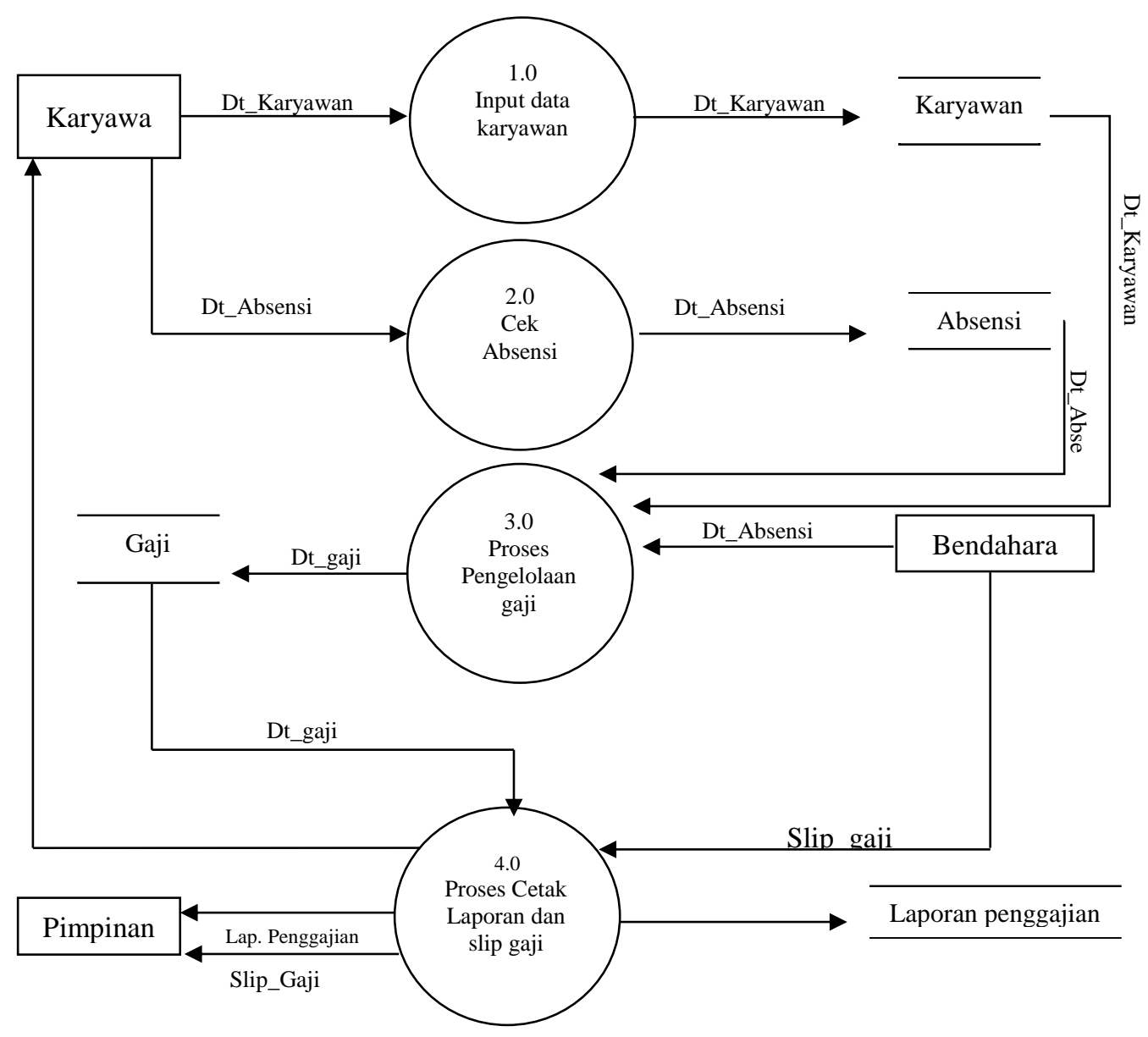

Gambar 3.2 Data Flow Diagram (DFD) Penggajian Karyawan 


\subsubsection{Entity RelationShip Diagram (ERD)}

Diagram hubungan entitas atau dikenal dengan diagram ER adalah rotasi grafik dari sebuah model data atau sebuah model jaringan yang menjelaskan tentang data yang tersimpan dari sebuah sistem.

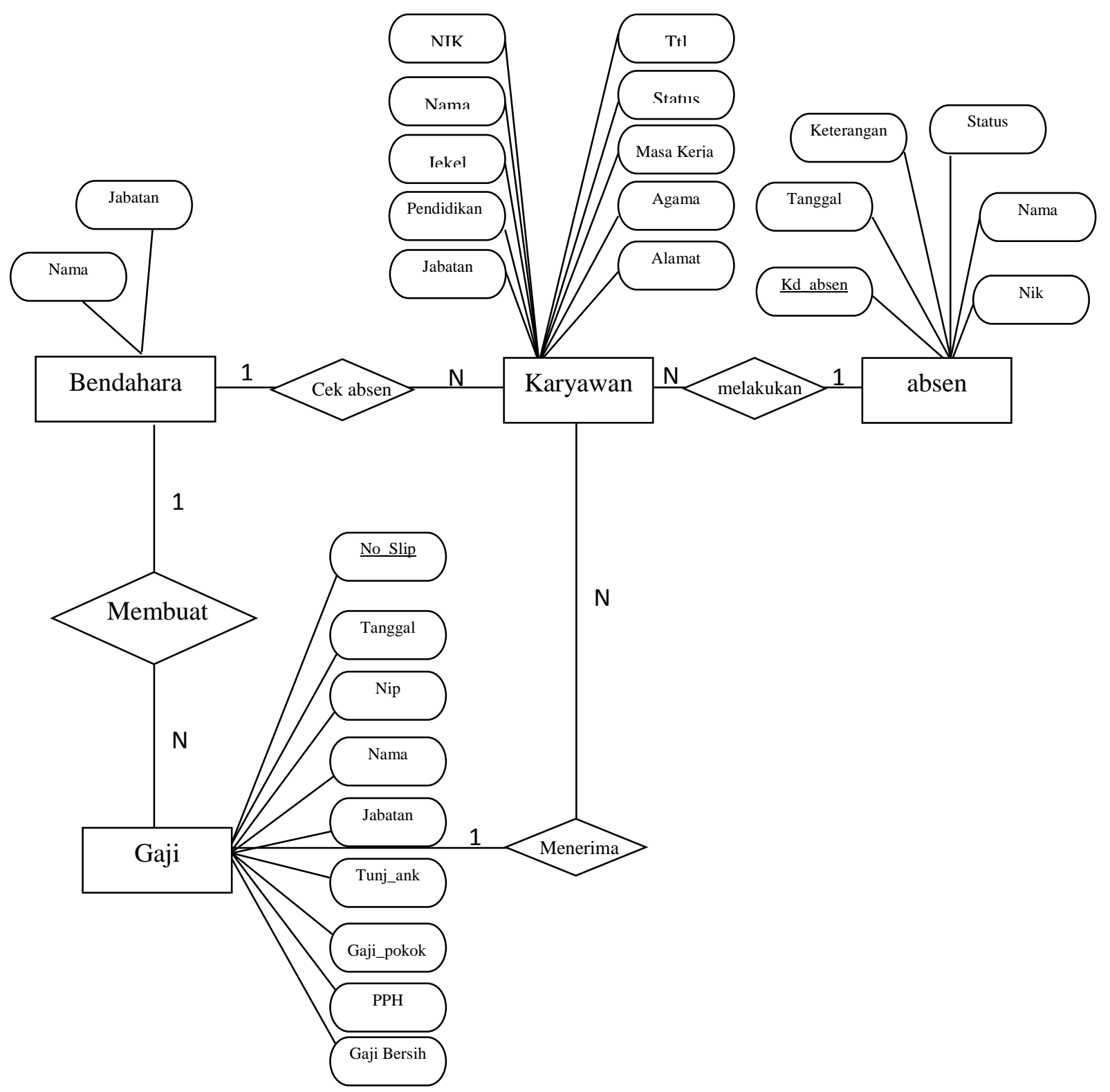

Gambar 3.3 Entity Relationship Diagram (ERD) 


\subsubsection{Flowchart Sistem Usulan}

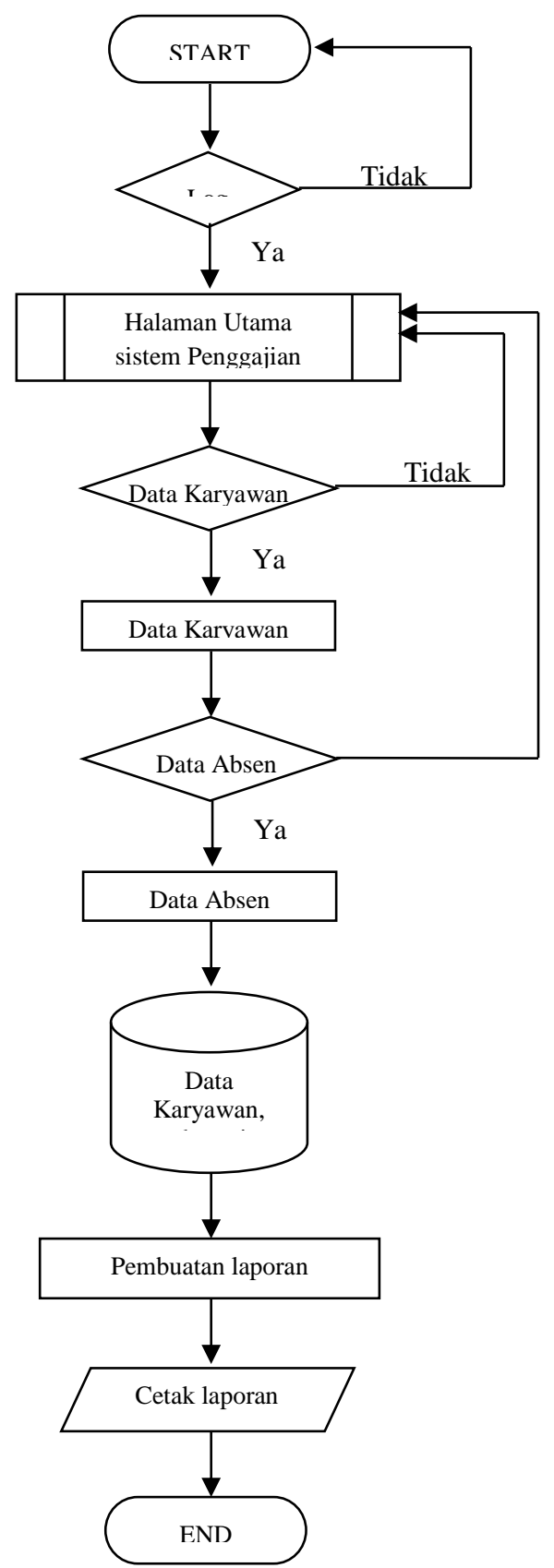

Gambar 3.4 Flowchart Sistem

\subsection{Implementasi Sistem}

Implementasi sistem adalah tahap penerapan sistem yang akan dilakukan jika sistem disetujui termasuk program yang telah dibuat pada tahap perancangan sistem agar siap untuk dioperasikan. Implementasi sistem merupakan tahap penerapan sistem agar sistem tersebut dapat digunakan/ dioperasikan untuk mencapai tujuan. 


\subsubsection{Implementasi Sistem Usulan}

1. Form Menu Utama

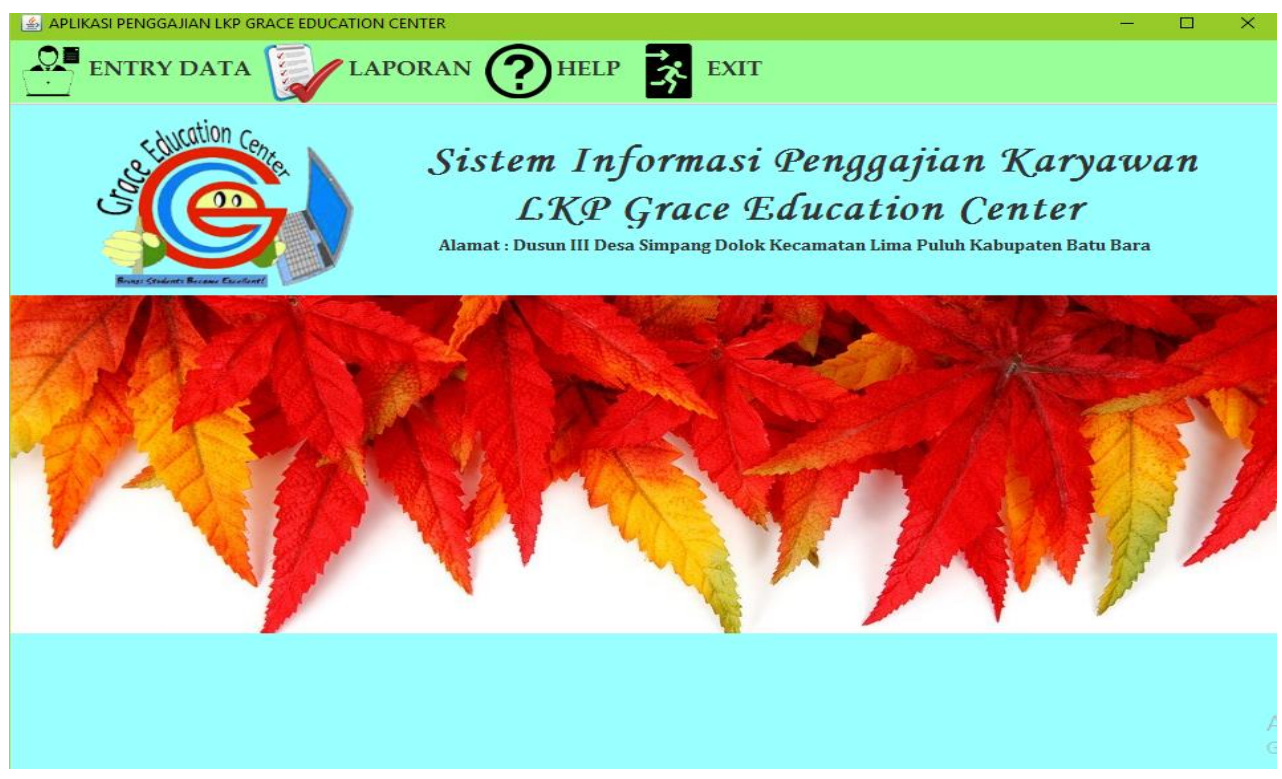

Gambar 3.5 Form Menu Utama

2. Form Input Data Karyawan

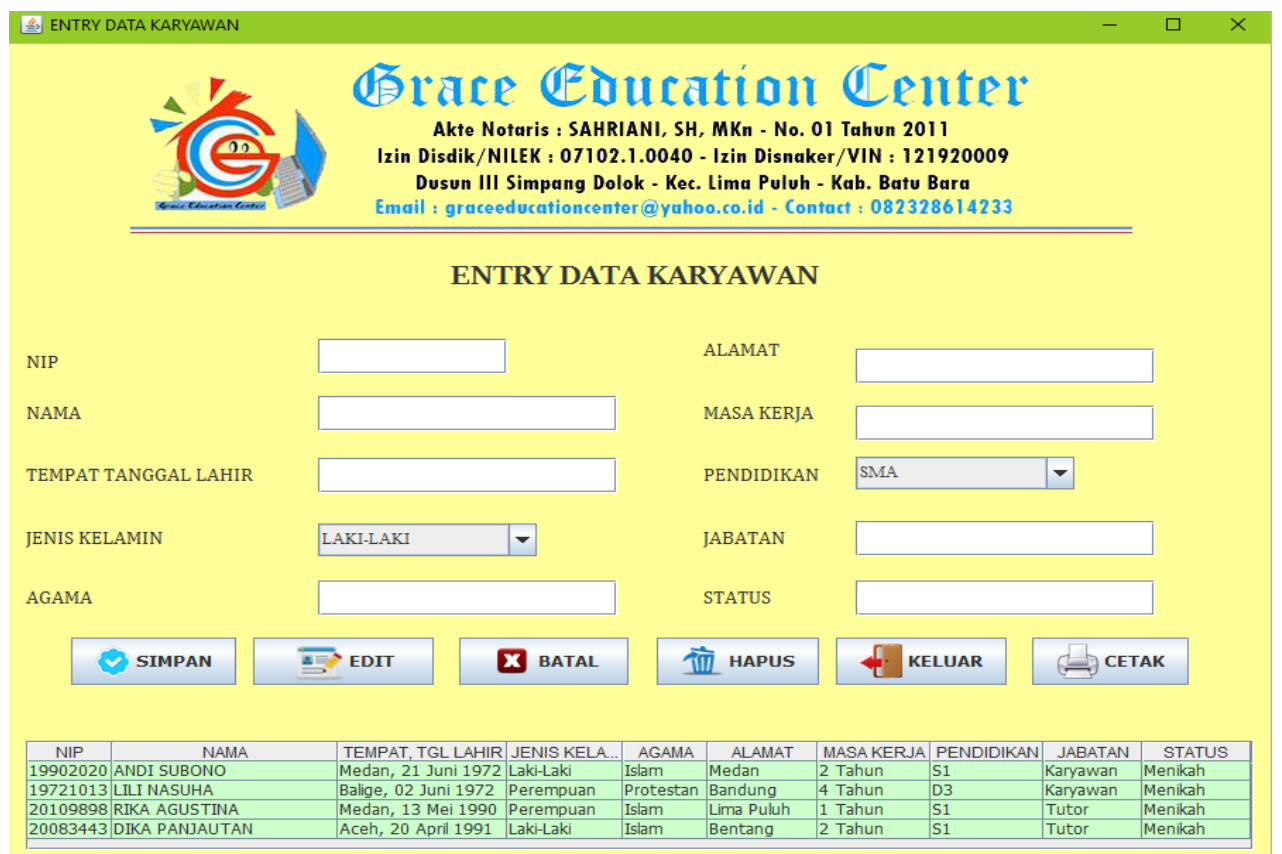

Gambar 3.6 Form Input Data Karyawan 
3. Form Input Data Absensi

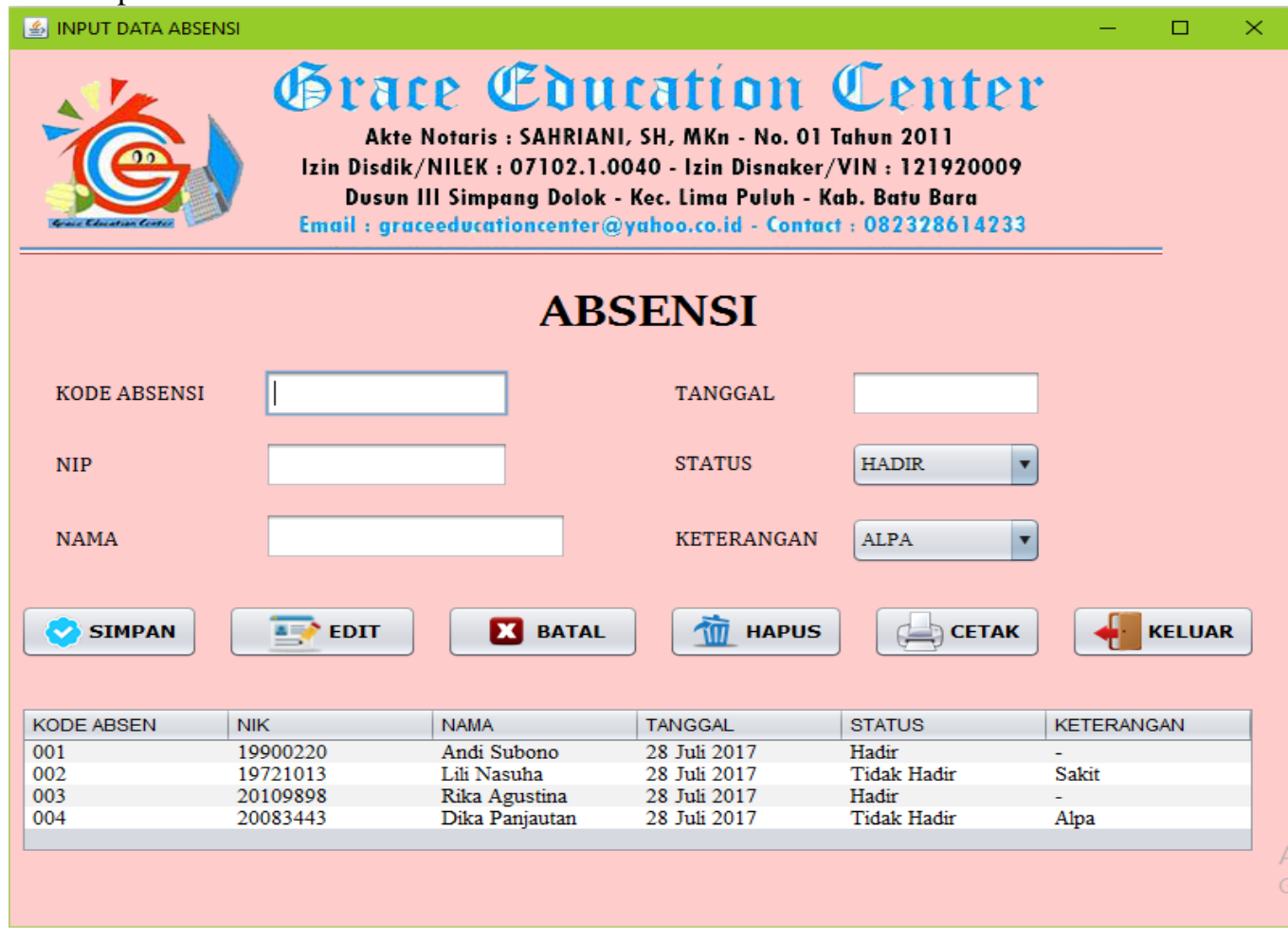

Gambar 3.7 Form Input Absensi

4. Form Input Data Gaji

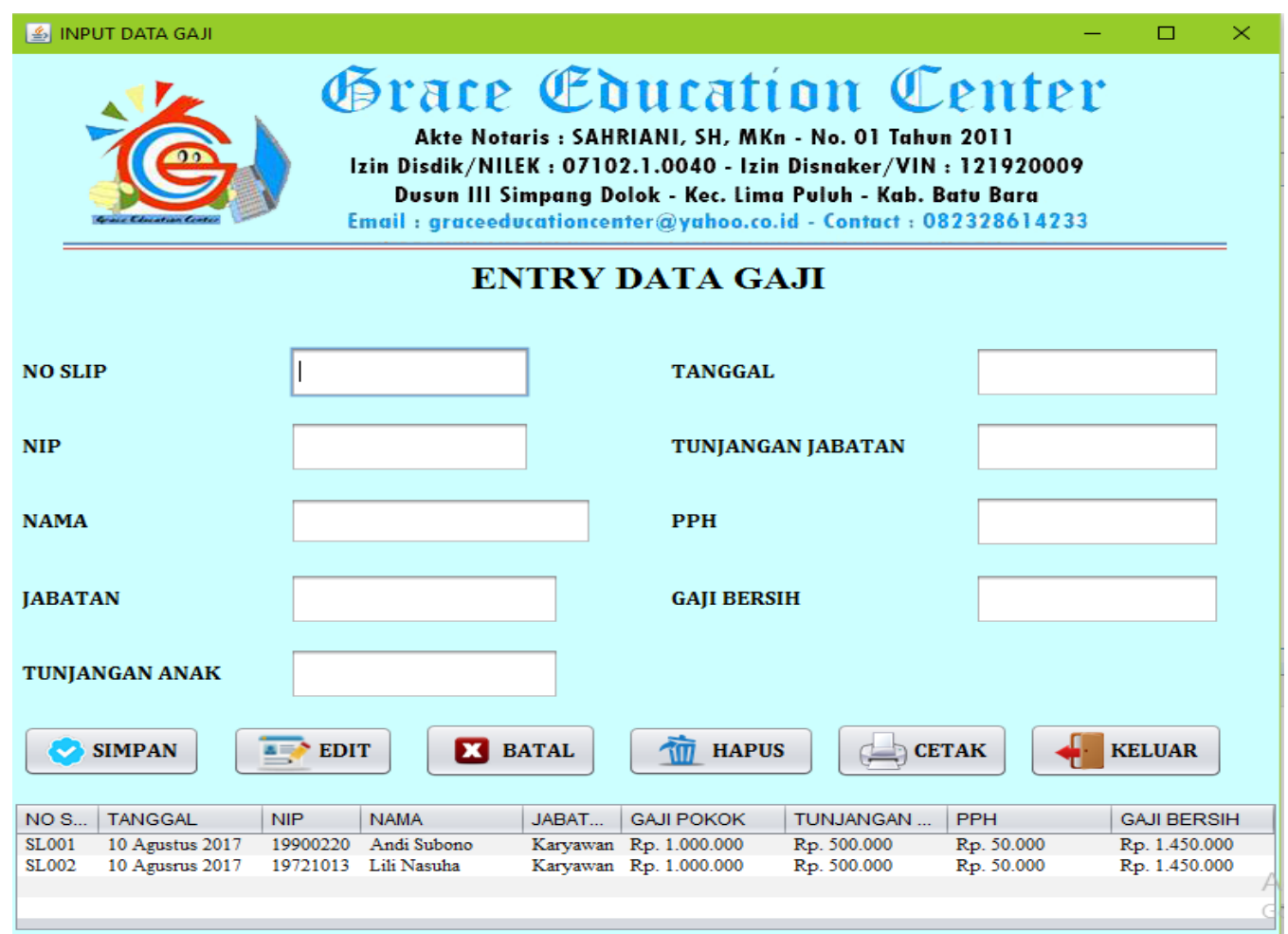

Gambar 3.8 Form Input Data Gaji 
5. Output Laporan Data Karyawan

\begin{tabular}{|c|c|c|c|c|c|c|c|c|c|}
\hline \multirow{2}{*}{\multicolumn{9}{|c|}{$\begin{array}{l}\text { Akte Notaris : SAHRIANI, SH, MKn - No. } 01 \text { Tahun } 2011 \\
\text { Izin Disdik/NILEK : } 07102.1 .0040 \text { - Izin Disnaker/VIN : } 121920009 \\
\text { Dusun III Simpang Dolok - Kec. Lima Puluh - Kab. Batu Bara } \\
\text { Email : graceeducationcenter@yahoo.co.id - Contact : } 082328614233\end{array}$}} & \multirow[t]{2}{*}{$\square$} \\
\hline & & & & & & & & & \\
\hline NIP & NAMA & TEMPAT, TGL LAHIR & JENIS KELA... & AGAMA & ALAMAT & MASA KER ... & PENDIDIK... & JABATAN & STATUS \\
\hline \multirow{5}{*}{$\begin{array}{l}19902020 \\
19721013 \\
20109898 \\
20083443\end{array}$} & ANDI SUBONO & Medan, 21 Juni 1972 & Laki-Laki & Islam & Medan & 2 Tahun & S1 & Karyawan & Menikah \\
\hline & LILI NASUHA & Balige, 02 Juni 1972 & Perempuan & Protestan & Bandung & 4 Tahun & D3 & Karyawan & Menikah \\
\hline & RIKA AGUSTINA & Medan, 13 Mei 1990 & Perempuan & Islam & Lima Puluh & 1 Tahun & S1 & Tutor & Menikah \\
\hline & DIKA PANJAUTAN & Aceh, 20 April 1991 & Laki-Laki & Islam & Bentang & 2 Tahun & S1 & Tutor & Menikah \\
\hline & & & & & & & $\Leftrightarrow$ CETAK & 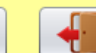 & KELUAR \\
\hline
\end{tabular}

Gambar 3.9 Output Laporan Data Karyawan

6. Output Laporan Data Absen Karyawan

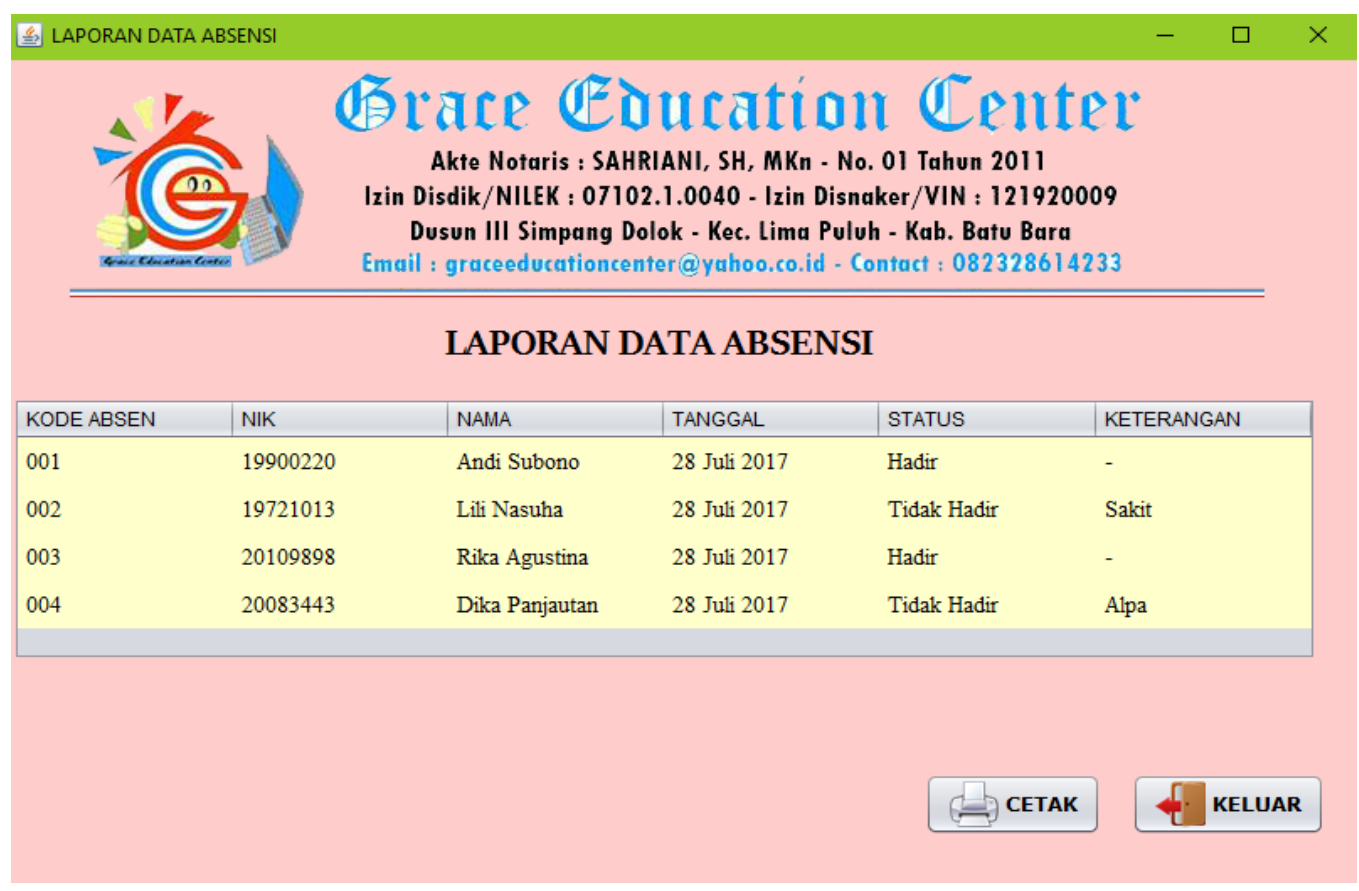

Gambar 3.10 Output Laporan Data Absensi Karyawan 
7. Output Laporan Data Absen Karyawan

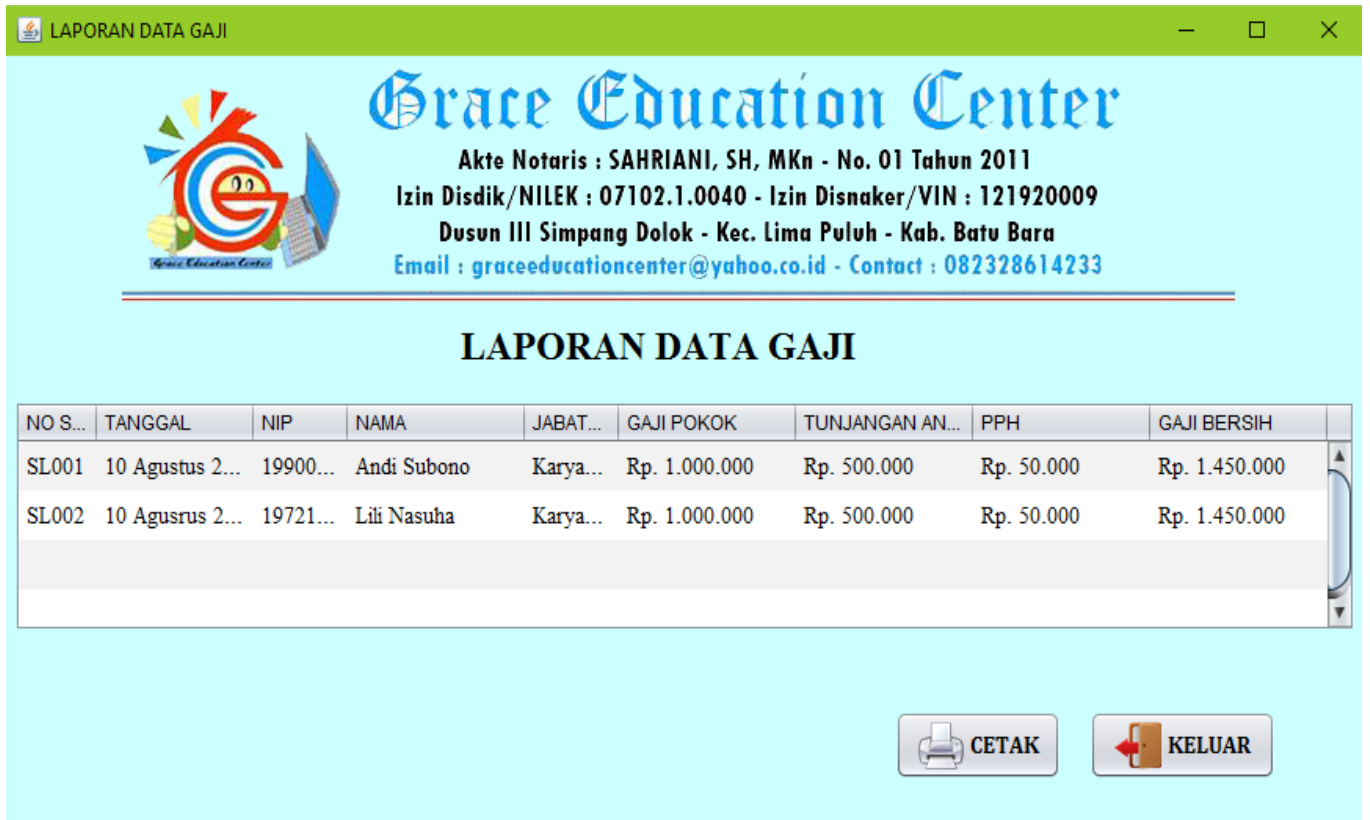

Gambar 3.11 Output Laporan Data Gaji Karyawan

\section{KESIMPULAN}

Dari hasil analisa Sistem Informasi Penggajian Pada LKP Grace Education Center maka dapat kesimpulan dari sistem baru tersebut sebagai berikut:

1. Bahwa dengan penggunaan sistem penggajian secara manual banyak mengandung resiko kesalahan pencatatan data. Sehingga sasaran sistem informasi yang diinginkan tidak dapat tercapai.

2. Informasi dapat diperoleh dengan cepat, tepat, dan akurat jika suatu waktu dibutuhkan sebagai bahan analisa bagi pihak yang bersangkutan.

3. Dapat mengurangi tingkat kesalahan pemahaman informasi Penggajian yang berlangsung di LKP Grace Education Center.

4. Memudahkan dalam pembuatan informasi yang dibutuhkan diantaranya Laporan Pegawai, Laporan Penggajian dan Slip Gaji secara cepat

\section{DAFTAR PUSTAKA}

[1] Devi Lestari, 2014. Perancangan Sistem Informasi Penggajian Karyawan Pada PR. Tunas Mandiri Kabupaten Pacitan. Indonesia Journal On Networking and Security. Volume 3 Nomor 4.

[2] Hall, James A, 2001. Sistem Informasi Akuntansi, Edisi Ketiga, Cetakan Pertama, Terjemahan : Amir Abadi Jusuf, Salemba Empat, Buku Satu, Jakarta.

[3] Hartono Jogiyanto. 2005. Analisis dan Desain Sistem Informasi Yogyakarta: Andi Offset.

[4] Muhammad Ilham, 2013. Perancangan Sistem Informasi Penggajian Pegawai Pada Kantor Bupati Kabupaten Aceh Barat Daya Dengan Menggunakan Bahasa Pemograman Visual Basic 6.0. Skripsi.

[5] Rifky Sahib Nugraha, 2009. Sistem Informasi Penggajian di PT. BPR Bali Rukun Mandiri. Tugas Akhir.

[6] Pengertian

Gaji. https://id.wikipedia.org/wiki/Gaji. diakses pada 07 Desember 2017.

[7] Zulnalis, 2016. Sistem Informasi Penggajian Karyawan (Studi Kasus : PT. Arus Global Security Service Jakarta). Jurnal Sistem Informasi STMIK Antar Bangsa.Volume V Nomor 2. 